\title{
T-Cell Lymphoma of Oral Cavity: A Case Report
}

\author{
Prashant $D^{1}$, Fatima $S^{2}$, Tiwari $N^{3}$, Prashant $V^{4}$ \\ ${ }^{1}$ Dr. Dolly Prashant, Associate Professor, Department of Pathology, Govt. Dental College, Raipur, CG, ${ }^{2}$ Dr. Fatima \\ Saify, Reader, Department of Oral Pathology, Govt. Dental College, Raipur, CG, ${ }^{3}$ Dr. Nidhi Tiwari, Lecturer, \\ Department of Oral Pathology, Govt. Dental College, Raipur, CG, ${ }^{4}$ Dr.ViplavPrashant, Assistant Professor, Department \\ of Biochemistry, Govt. Dental College, Raipur, CG, India
}

Address for Correspondence: Dr. Viplav Prashant, Email: drviplav2004@gmail.com

\begin{abstract}
Malignant lymphomas are heterogenous group of neoplasms of lymphoid tissues with different clinical courses and varied prognosis. Non-Hodgkin's lymphoma (NHL) often presents at the extranodal sites of head and neck region, but the intraoral lesions are much less frequent, especially when they are the only manifestation of the disease. The oral cavity including the palate, gingiva, tongue, buccal mucosa, floor of the mouth and lips are the primary sites for approximately $2 \%$ of all extranodal lymphomas. We here report the case of a 40 years old male that had initial extra nodal intraoral presentations undiagnosed previously. The clinical, histopathological and immunological examinations revealed T-cell lymphoma.
\end{abstract}

Keywords: Extranodal, Non-Hodgkin's lymphoma, Oral cavity, Soft palate, Hard palate.

\section{Introduction}

Lymphomas are a heterogenous group of clonal malignant neoplasms of lymphocytic cell line known for their spectrum of behaviour ranging from relatively indolent to highly aggressive and potentially fatal course. They are broadly classified as Hodgkin's lymphoma (HL) and Non-Hodgkin's lymphoma. Primary NHL usually arises within the lymph nodes but $20-30 \%$ accounts for the extra nodal sites [1]. The incidence of oral NHL is about $0.1 \%$ to $5 \%$ [2]. Oral NHL can involve the paranasal sinuses but can also arise from within the soft tissue or bone, gingiva, floor of mouth, salivary glands and cheek [3]. Majority of adult NHL (about 79\%) are of B-cell origin while the rest belong to $\mathrm{T}$ cell or NK cell type but according to other studies the incidence of B cell lymphoma is even higher [4]. Owing to scarcity of reported cases, the diagnosis and understanding of the biological behaviour of oral NHL becomes difficult and therapeutic options are therefore limited. A thorough clinical, histopathological and immunohistochemical evaluation is essential for the diagnosis and management of oral NHL.

Manuscript received: $22^{\text {nd }}$ Feb 2016

Reviewed: $28^{\text {th }}$ Feb 2016

Author Corrected: $10^{\text {th }}$ March 2016

Accepted for Publication: $20^{\text {th }}$ March 2016

\section{Case Report}

A 40 years old male presented with a unilateral swelling at the upper left quadrant of oral cavity, at the junction of soft and hard palate. On examination, the swelling was 4 X $4 \mathrm{cms}$ in size, bluish red in colour, sessile, nontender on palpation, with smooth surface and welldefined margins. There was no other swelling in the oral cavity, no cervical or axillary lymphadenopathy or any other positive findings.

The radiographic and clinical examination revealed no other significant finding. The conclusion that the lesion was primarily in the oral cavity was made. The biopsy of the lesion was taken for confirmation of the diagnosis. The histopathogical and immunohistochemical studies revealed that the lesion was T cell lymphoma of oral cavity.

\section{Discussion}

Lymphoma is the third most common neoplasm of head and neck region; the first two being squamous cell carcinoma and salivary gland neoplasms [5]. Lymphomas arise due to mutation of progenitor cells of lymphoid lineage, that can be determined by 
immunophenotyping and genetic arrangement studies and various etiologies have been suggested. The incidence of oral lymphoma is rare and is approximately $2 \%$ of all extranodal lymphomas [6]. Gulley et al [7] suggested the role of EBV in oral lymphomas. Also, it has been reported that there is an increased rate of lymphoma in patients who are congenitally immunocompromised and in patients who receive immunosuppressive therapy [8].

Almost $23 \%$ of patients with NHL presented with involvement of an extranodal head and neck site [9]. The most common site involved in oral cavity is palate and gingiva [10], however, lymphomas of other sites have also been reported $[11,12]$. It is uncommon for NHL to appear first or only orally. Primary occurrence of NHL in oral mucosa is rare and when oral soft tissue lesions appear for the first time ,they are generally nontender, soft to firm swelling of the area often with overlying ulcerations [13], and they are often characterized by an absence of other symptoms $[8,14$, 15].

Enrique et al [16] has reported that the incidence of involvement of cervical lymph nodes in HL is $100 \%$ and in NHL is $86.6 \%$. Abdominal adenopathies may be found in 50\% patients of head and neck NHL [16]. The varied presentation of the disease provides a diagnostic dilemma owing to the protean manifestation of its presentation. It may present with nasal obstruction, rhinorrhoea, hypoacousia and cranial nerve palsies. Most lesions occur in Waldeyer's ring and occurrence in oral cavity is very rare [1]. Our patient had lesion in the palate region including both hard and soft palate.

The signs and symptoms suggestive of lymphoma in the head and neck region are the presence of numbness, tooth mobility, swelling, unexplained dental pain or illdefined lytic osseous changes [17]. Other differential diagnosis includes a dental abscess, periodontal infection or benign reactive hyperplasia. Our patient presented with a non-tender swelling, gingivitis, tooth mobility but as the swelling was progressive, incisional biopsy of the lesion was done and diagnosis of lymphoma was made which on further confirmation with immunohistochemistry turned out to be $\mathrm{T}$ cell lymphoma.

Lymphoma presents mainly in older adults [4] and there is a logarithmic increase in incidence with increasing age [18]. Also, male gender is commonly involved [10].
In our case also the patient was a 40 years old middle aged male.

Various classifications and staging systems have been suggested including working formulation classification, REAL classification, WHO classification, IPI and Ann Arbor staging system, and NCI proposed grading [19, 20, 21].

The diagnosis of oral extranodal NHL is difficult owing to the versatility of its presentation and low index of suspicion. Incisional biopsy coupled with immunological studies of biopsied tissue is a definitive diagnostic modality [22]. CT scan of head and neck, chest, abdomen and pelvis are the mainstay of staging oropharyngeal extranodal lymphomas.

Investigations for immunocompromised patients like HIV and EBV infections should be examined because oral cavity is preferred site for extranodal NHL. Concurrent immunohistochemistry is useful for distinguishing cell types further confirming the diagnosis [1]. In our patient, histopathological examination revealed monoclonal proliferation of lymphocytes in a chronic inflammatory background (Figure 1).

Immunohistochemistry showed that the tumour cells were strongly immunopositive for CD3 (Figure 2) and CD5 (Figure 3), focal positive for CD45 (Figure 4), and negative for CD19 and CD20. The diagnosis of T cell lymphoma of oral cavity was made. The patient was seronegative for HIV. He was asked for follow-up after the investigations but he did not turn up.

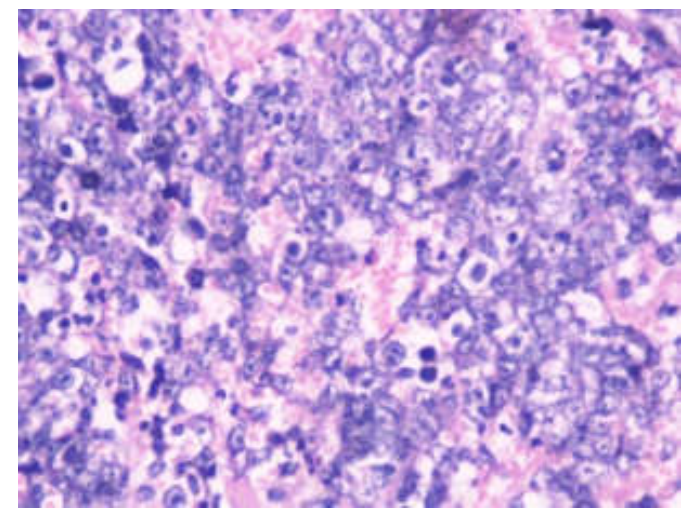

Figure 1: H \& E stain 10X: Monoclonal proliferation of lymphocytes 


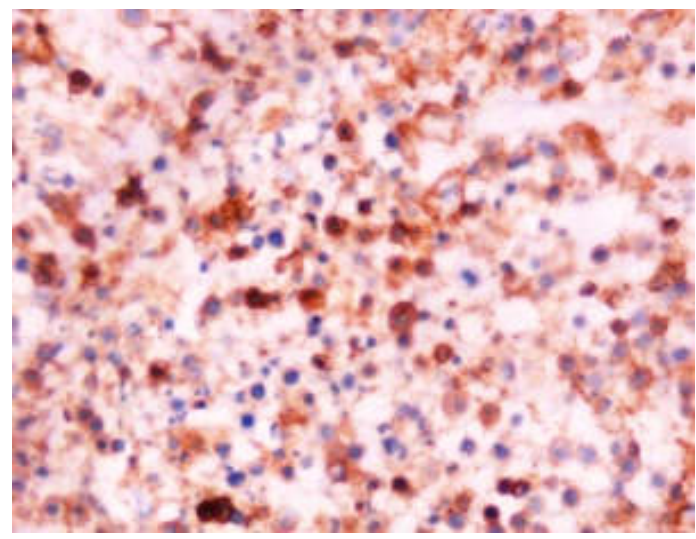

Figure 2: CD3 positive 40X

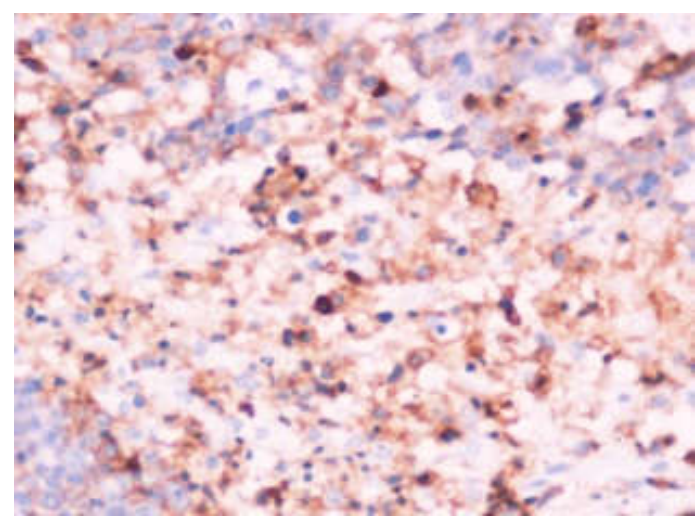

Figure 3: CD5 positive 10X

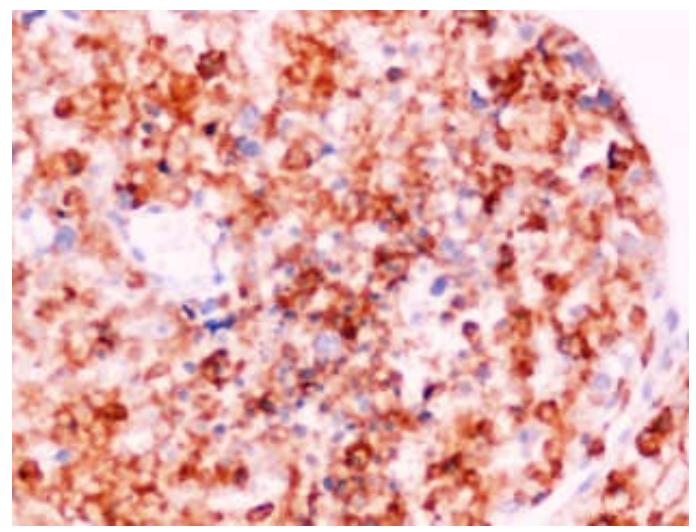

Figure 4: CD45 Focal positivity $10 \mathrm{X}$

Primary oral NHL is a rare entity though it is a preferred site in immunocompromised patients. In immunocometent patients, the diagnosis is difficult due to low index of suspicion. Chemotherapy is the mainstay of treatment. Anti-retroviral therapy (ART) along with chemotherapy is indicated in HIV positive cases. It is the responsibility of the dentists, paediatricians, clinicians and oral \& maxillofacial surgeons who treat these patients to be aware of this rare possibility as correct diagnosis is very essential for appropriate treatment at an early stage of the disease.

Funding: Nil, Conflict of interest: None.
Permission of IRB: Yes

\section{References}

1.Vinoth PN, Selvan SM, Sahni L, Krishnaratnam K, Rajendiran S, Anand CV, Scott JX. Primary extra nodal non-Hodgkin's lymphoma of the oral cavity in a young girl. Natl J Maxillofac Surg. 2012 Jul;3(2):187-9. doi: 10.4103/0975-5950.111377.

2. Spatafore CM, Keyes G, Skidmore AE. Lymphoma: an unusual oral presentation. J Endod. 1989 Sep;15(9):438-41.

3.Ratech H, Burke JS, Blayney DW, Sheibani K, Rappaport H. A clinicopathologic study of malignant lymphomas of the nose, paranasal sinuses, and hard palate, including cases of lethal midline granuloma. Cancer. 1989 Dec 15;64(12):2525-31.

4. Yin HF, Jamlikhanova V, Okada N, Takagi M. Primary natural killer/T-cell lymphomas of the oral cavity are aggressive neoplasms. Virchows Arch. 1999 Oct;435(4):400-6.

5. Griffin TJ, Hurst PS, Swanson J. Non-Hodgkin's lymphoma: a case involving four third molar extraction sites. Oral Surg Oral Med Oral Pathol. 1988 Jun;65(6):671-4.

6.Kobler P, Borcic J, Filipovic ZI, Nola M, Sertic D. Primary non-Hodgkin's lymphoma of the oral cavity. Oral Oncology Extra. 2005;41:12-4.

7. Sargeant KP, Grider DJ, Eagan PA, Davey DD, Damm DD, Robinson RA, et al. Lymphomas of the oral soft tissues are not preferentially associated with latent or replicative Epstein-Barr virus. Gulley M.L; Oral surgery, oral medicine, oral pathology, oral radiology, and endodontics ISSN 1079- 2104 Source / Source Congrès American Academy of Oral Medicine. Annual meeting. 1995;80:420-31.

8. Gedik R, Gedik S, Göze F, Develioglu H. Lymphoma in the infraorbital region. J Am Dent Assoc. 2003 Oct;134(10):1353-5. 
9. Urquhart A, Berg R. Hodgkin's and non-Hodgkin's lymphoma of the head and neck. Laryngoscope. 2001 Sep;111(9):1565-9.

10. van der Waal RI, Huijgens PC, van der Valk P, van der Waal I. Characteristics of 40 primary extranodal non-Hodgkin lymphomas of the oral cavity in perspective of the new WHO classification and the International Prognostic Index. Int J Oral Maxillofac Surg. 2005 Jun;34(4):391-5.

11. Maheshwari GK, Baboo HA, Gopal U, Wadhwa MK. Primary extra-nodal non-Hodgkin's lymphoma of the cheek. J Postgrad Med. 2000 Jul-Sep;46(3):211-2.

12. Pazoki A, Jansisyanont P, Ord RA. Primary nonHodgkin's lymphoma of the jaws: Report of 4 cases and review of the literature. J Oral Maxillofac Surg. 2003 Jan;61(1):112-7.

13. Jayakrishnan R, Thomas G, Kumar A, Nair R. NonHodgkin's lymphoma of the hard palate. J Oral MaxillofacPathol. 2008;12:85-7.

14. Margiotta V, Franco V, Rozzo A, Porter S, et al. Gastric and gingival localization of mucosa-associated lymphoid tissue (MALT) lymphoma. An Immunohistochemical, virological and clinical case report. J. Periodontol., 70 (1999), pp. 914-918.

15. Koga M, Kusukawa J, Hayabuchi N. Spontaneous regression of extranodal malignant lymphoma occurred in the gingiva. Oral Oncol. 2003 Apr;39(3):323-4.
16. Enrique A, Quesada JL, Lorente J, López D. [Hodgkin and Non-Hodgkin lymphomas in otorhinolaryngology]. Acta Otorrinolaringol Esp. 2004 Oct;55(8):387-9.

17. Angiero F, Stefani M, Crippa R. Primary nonHodgkin's lymphoma of the mandibular gingiva with maxillary gingival recurrence. Oral Oncol Extra. 2006;42:123-8.

18. Ferlay J, Bray F, Pisani P, Parkin DM. 2001. Lyon: IARC; GLOBOCAN 2000: cancer incidence, mortality and prevalence worldwide, version 1.0 IARC cancer Base No. 5, Lyon: IARC, 2001.

19. Harris NL, Jaffe ES, Stein H, Banks PM, Chan JK, Cleary ML, et al. A revised European American classification of lymphoid neoplasms: A proposal from the international study lymphoma group. Blood. 1994;84:1361-92.

20. Harris NL, Jaffe ES, Stein H, Vardiman JW. World Health Organisation Classification of Tumours. Pathology and genetics of tumours of the haemopoetic and lymphoid tissues. Lyon: IARC press; 2001.

21. Carbone PP, Kaplan HS, Musshoff K, Smithers DW, Tubiana M. Report of the Committee on Hodgkin's Disease Staging Classification. Cancer Res. 1971 Nov;31(11):1860-1.

22. Rooney N, Ramsay AD. Lymphomas of the head and neck. 2; The B-cell lymphomas. Eur J Cancer B Oral Oncol. 1994 May;30B(3):155-9.

\section{How to cite this article?}

Prashant D, Fatima S, Tiwari N, Prashant V. T-Cell Lymphoma of Oral Cavity: A Case Report. Int J Med Res Rev 2016;4(3):397-400. doi: 10.17511/ijmrr.2016.i03.20 